\title{
Assessing the accuracy of the pixel-based algorithms in classifying the urban land use, using the multi spectral image of the IKONOS satellite (Case study, Uromia city)
}

\author{
Esmaeel Safaralizade ${ }^{1}$, Robab Husseinzade $^{2}$, Gholamhussein Pashazade ${ }^{1}$, \\ Bakhtiar Khosravi ${ }^{1, *}$ \\ ${ }^{1}$ Department of Geography, Payame Noor University, PO BOX 19395 - 3697, Tehran, Iran \\ ${ }^{2}$ Department of Geographic Information Systems (GIS), Shahihd Beheshti University, Tehran, Iran \\ *E-mail address: bakhtar.khosravi@yahoo.com
}

\begin{abstract}
With the development of urbanization and expansion of urban land use, the need to up to date maps, has drawn the attention of the urban planners. With the advancement of the remote sensing technology and accessibility to images with high resolution powers, the classification of these land uses could be executed in different ways. In the current research, different algorithms for classifying the pixel-based were tested on the land use of the city of Urmia, using the multi spectral images of the IKONOS satellite. Here, in this method, the algorithms of the supervised classification of the maximum likelihood, minimum distance to mean and parallel piped were executed on seven land use classes. Results obtained using the error matrix indicated that the algorithm for classifying the maximum likelihood has an overall accuracy of 88/93\% and the Kappa coefficient of 0/86 while for the algorithms of minimum distance to mean and parallel piped, the overall accuracy are $05 / 79 \%$ and $40 / 70 \%$ respectively. Also, the accuracy of the producer and that of the user in most land use classes in the method of maximum likelihood are higher compared to the other algorithms.
\end{abstract}

Keywords: Land use; Pixel-based; IKONOS; Uromia; Classification

\section{INTRODUCTION}

Remote sensing is the art and science of obtaining information about objects, zones and phenomena through analyzing data obtained without physical contact with the object or zone under investigation (Bakker et al, 2001). In fact remote sensing is complex impression of the earth level where the special properties of herbs, earth and the atmosphere are combined together so that an overall reflection of the land level ecosystem is registered (Alavipanah et al, 2008).

Today, remote sensing multi spectral sensors are designed to get the energy reflected of different ground objects in the visible and infrared wavelengths of the electromagnetic spectrum. These digital sensors have converted the reflected energy of ground zones to digital 
numbers, generally constituting the image (Navulur, 2007). The remote sensing imagery, deals with studying the spectral properties of different phenomena and presents capabilities inn comprehending, predicting, managing and making decisions about land resources (Matinfar et al, 2007).

Today, these images are known to be the most recent information to study land use and coverage and are belied to be the main preconditions for optimal use of the land and getting information about land paradigms (Feizezade, 2007). In fact, the land use of exploitation ways of the land are thought to be very much important to remove various needs and to get knowledge of the land use for managerial activities and planning (Lillesand et al, 2004). The land use coverage classification of data with high resolution remote sensing power derives from the special and spatial heterogeneity of such imagery (Taubenbock, et a, 2006). Multi spectral satellites with high resolution like IKONOS show the details based on the urban maps and thus have higher potential in getting a full digital images of the urban environment(Herald and Scephan, 2002).

The aim of classifying the image is to determine the pixels in images along with significant information of the real world. When remote sensing image classification is done, thematic maps such as the type of land and satellite images are substantive because of a digital nature, providing all out visionary, repeated coverage and picture information. In the pixel based classification method, the supervised and unsupervised classification algorithms are used that rely on the numerical values of the pixel itself. Of the most important algorithms of supervised pixel-based classification, one can refer to the maximum likelihood, minimum distance to mean and to parallel piped. Karami (2002), in his M.A. thesis, has dealt with the classification of object-orientation by the Land sat ETM+ imagery of the Malayer region and concluded that the object-oriented classification method compared to the pixel-based method with the algorithm of maximum similarity engenders better results, because it applies both spatial and spectral data with one another. Matinfar et al, 2007, studied the land coverage of the Kashan region by using six bands of Land sat 7 ETM+ imagery through pixel-based and object-oriented classification methods.

They concluded that the pixel-based classification method with an overall accuracy of $81 \%$ provides more accurate results. Martin Herald and Joseph Scephan (2002), using the IKONOS multi spectral images and based on object-oriented algorithms and using 11 spectrum classes, began to formulate a map of the land use of Santa Barbara city.

The overall accuracy obtained was $79 \%$. Renad Mathew and Jaguant Ariel (2005) began to extract a map of the herbal coverage of the city Dunedin in New Zealand by way of IKONOS multi spectral images and object-orientation and classifying the nearest neighbor . Here, the overall accuracy of the classification and the Kappa coefficient were $92 \%$ and 89 $\%$ respectively. Jing Qian et al, (2007), by using the Landsat ETM+ imagery in order to extract built in zones in an arid region began to compare pixel- based classification methods where the results indicated that applying satellite pictures in classifying urban land use could be platform for formulating up to date maps .

In accordance with different land use, in the city of Urmia, and the increasing urban development (15 square kilometers in 1974, 37 square kilometers in 1986, and over 50 square kilometers in 2004), the need to the urban land use mapping with high accuracy seems necessary. Thus, in the present research, by using the multi-spectral IKONOS satellite, different pixel- based algorithms in classifying an providing land use mapping of the city in question are compared in order that the potential capability if these data in investigated to classify the urban land use and it is used as a guideline for the urban land use planners. 


\section{MATERIAL AND PROCEDURES}

\section{1. Region under study}

The region under study is the city of Urmia, the center of the western Azerbaijan province and the center of Urmia located in the northwest of the country.

This city is located in the geographic longitude of 45 degrees and 4 minutes and 45 seconds eastern and in the geographic latitude of 37 degrees and 33 minutes and 15 seconds northern in the west of Urmia river with the medium height of 1332 meters of the sea level. Coordinate of the four corners of the region under s follows: Up: 4159732; Left: 504280; Right: 508376; Down: 415636.

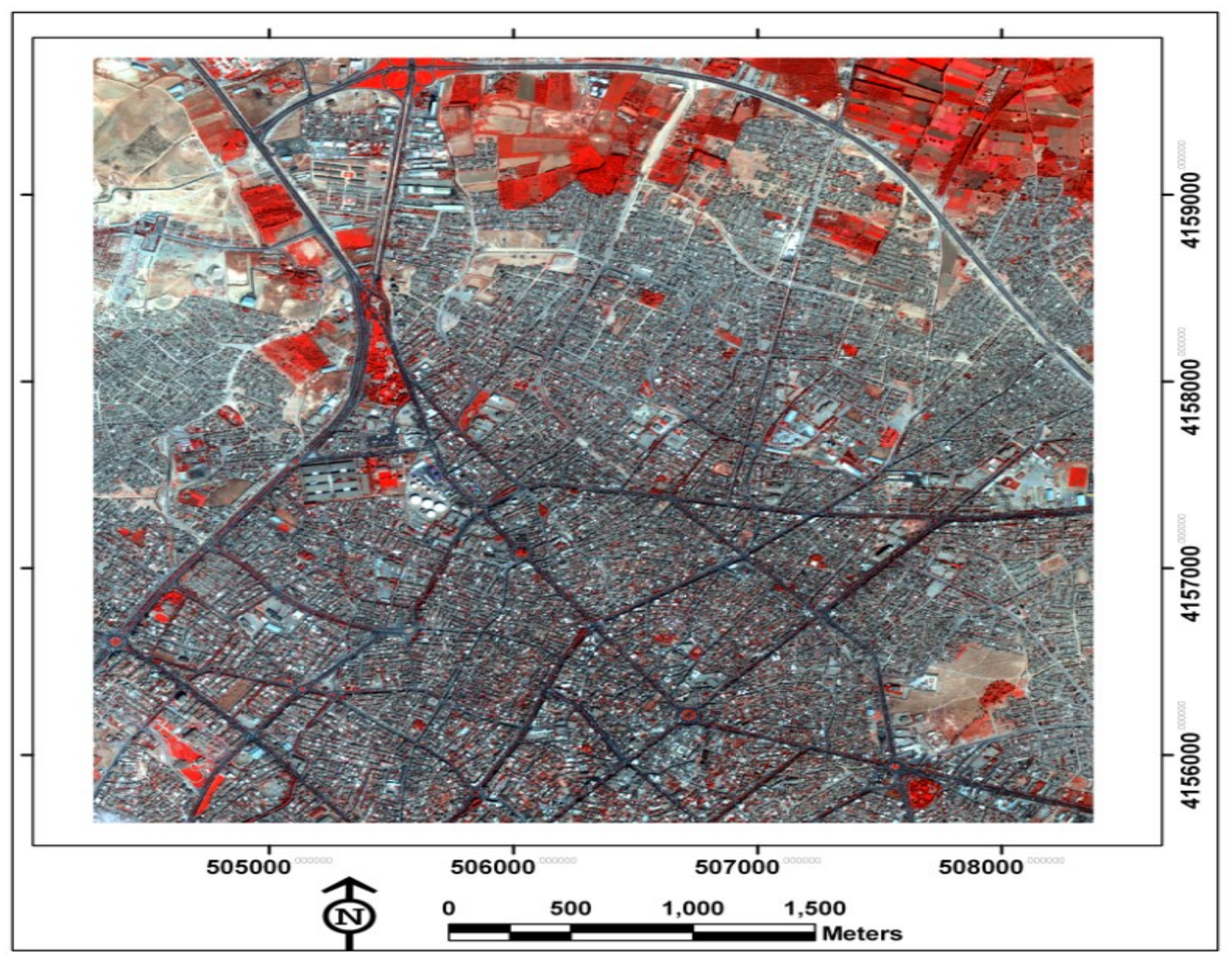

Figure 1. The location of the region under study in the country and in the province. 

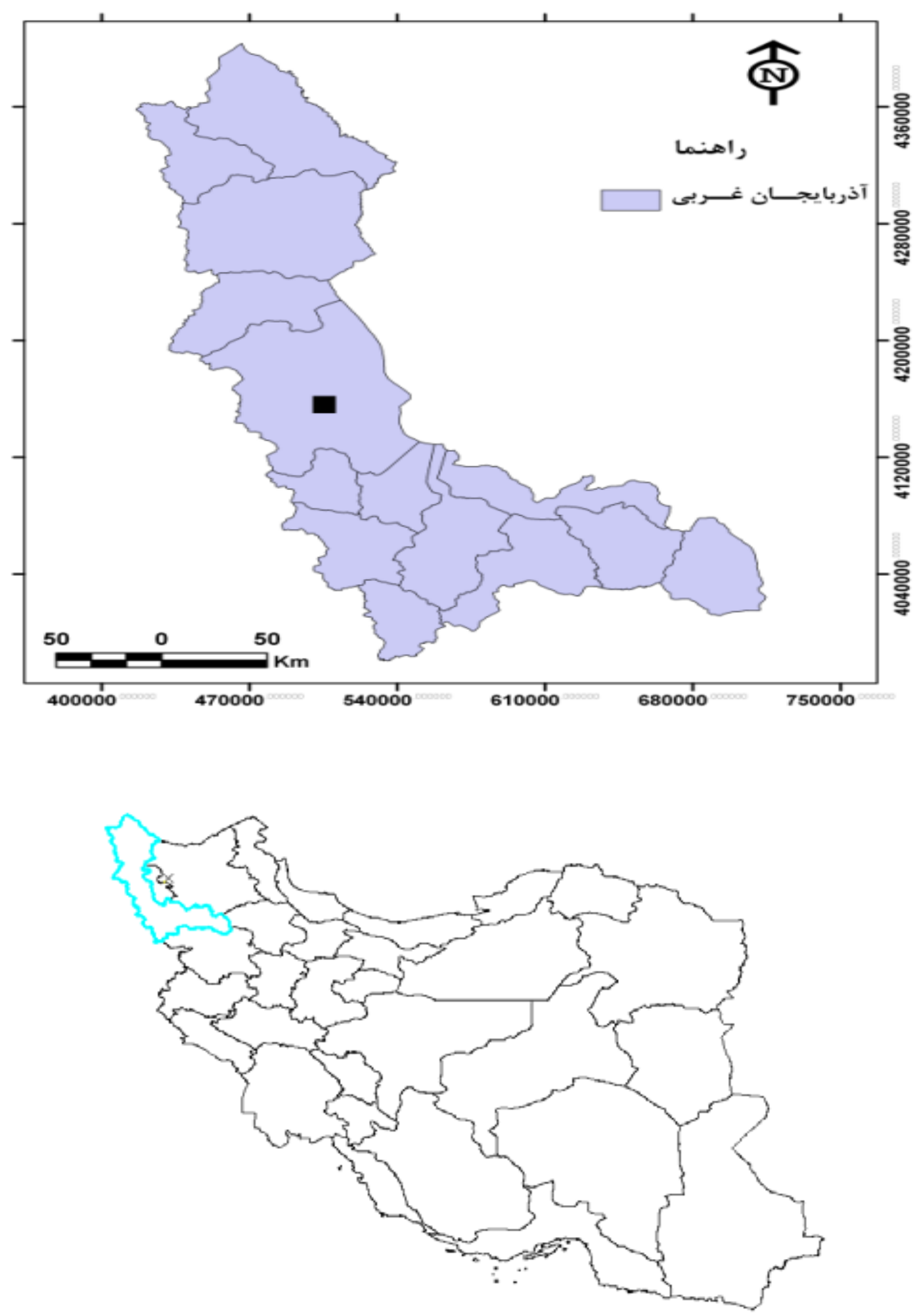

Figure 1(cuntinue). The location of the region under study in the country and in the province. 


\section{2. IKONOS satellite images}

In this research, an IKONOS satellite pictures frame was used along with multi spectral bands with pixel- dimensions in 4 meters, in order to apply classification methods . Pictures coordinate, UTM (universal transverse Mercator) with oval base of WGS84 and zone 38. This picture, was taken in 2003, on October, the second. The properties related to the picture under study are shown in Table 1.

Table 1. Features of the IKONOS image under study.

\begin{tabular}{|c|c|c|c|c|}
\hline Band & $\begin{array}{c}\text { Spectral region } \\
\text { (nanometer) }\end{array}$ & $\begin{array}{c}\text { Spatial high } \\
\text { resolution (meter) }\end{array}$ & $\begin{array}{c}\text { Spatial high } \\
\text { resolution in } \\
\text { nadir (meter) }\end{array}$ & Image depth \\
\cline { 1 - 3 } $\begin{array}{c}\text { Blue spectral } \\
\text { band }\end{array}$ & $445-516$ & 4 & \multirow{2}{*}{$3 / 2$} & \multirow{2}{*}{16 bits } \\
\cline { 1 - 2 } $\begin{array}{c}\text { Breen } \\
\text { spectral band }\end{array}$ & $506-595$ & 4 & & \\
\cline { 1 - 3 } $\begin{array}{c}\text { Red spectral } \\
\text { band }\end{array}$ & $632-698$ & 4 & & \\
\cline { 1 - 2 } $\begin{array}{c}\text { Infra spectral } \\
\text { band }\end{array}$ & $758-853$ & 4 & & \\
\hline
\end{tabular}

\section{3. Research objectives}

The objectives in the research are as follow:

a) Compare the accuracy of methods for classifying the urban land use

b) Access a cheap method with relatively high accuracy in classifying the land use classes

\section{RESEARCH METHOD}

Here, in this research, the region under study, has been covered by an IKONOS Satellite picture frame whose processing level is geo and geometric corrections on the picture were applied using the 17 control points with appropriate transmittance with RMSe equal to $0 / 6$ pixel. The pixel based classification was done by using the algorithms of classifying the maximum made the use of PCI Geomatic 9.0 and ENVI, 4.8. To do this, with these algorithms, the training samples were used to test the classification. The pixel-based accuracy was obtained by comparing the classified pixel-samples with ground information by the way of Error matrix.

\section{1. Image classification}

The act of separating similarity, spectral sets and their class divisions, having similar special behavior is called satellite information classification. The classification method could been done in two ways: supervised and unsupervised. The supervised classification needs the previous information and the recognition of phenomena relevant with data. In this method, 
some of the pixels are selected as indicators and samples and their features enter the computer through the software in use. Accordingly, the computer classifies the rest of the pixels in accordance with a special guideline that is provided (Alavipanah, et al, 2008). The process of classifying the image includes 5 stages (chart 1):

1. Choosing and preparing the picture data,

2. Defining and specifying clusters in the common spaces,

3. Choosing the classification algorithm,

4. Executing the classification,

5. Validation of the results (Janssen, 2001).

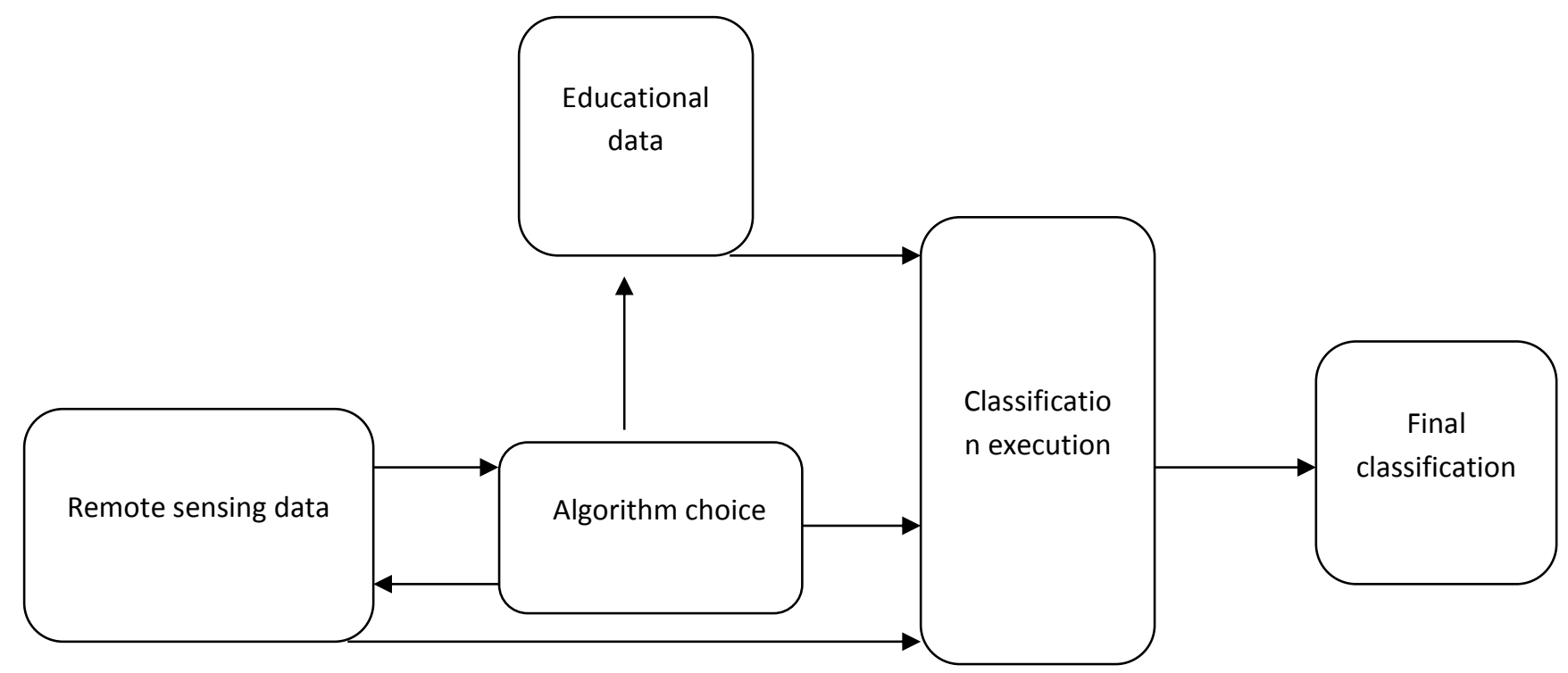

Chart 1. The process of image classification.

\section{2. The classification algorithm of minimum distance to mean}

In this method, first the average spectral values are determined in each band and for each class and the pixel after being specified and that has assigned to itself the average spectral value of the selected samples of each class, the distance of each unclassified pixel is compared to the average pixels and then the pixel is assigned to a class, having the least distance to that mean (Alavipanah et al, 2008). The method of minimum distance to the mean is mathematically easy and computationally efficient while it is not sensitive towards various change degrees in data with spectral response (Lillesand, and Kiefer, trans. by Malmiran, 2001). This method often presents better accuracy in a situation where there are few specific pixels for the classes. This method, without using information like variance, attempts to divide the multi spectral areas, thus, it'll be weak in modeling the classes and it should apply more spectral classes to make up for the weakness (Fatemi and Rezaee, 2006).

Figure 2. Indicates this algorithm. Often in this algorithm, the Euclidean distance, standardized Euclidean distance and the Mahalanobis distance are used (The Japanese remote sensing association, trans. by Jahedi and Farokhi, 1997). 


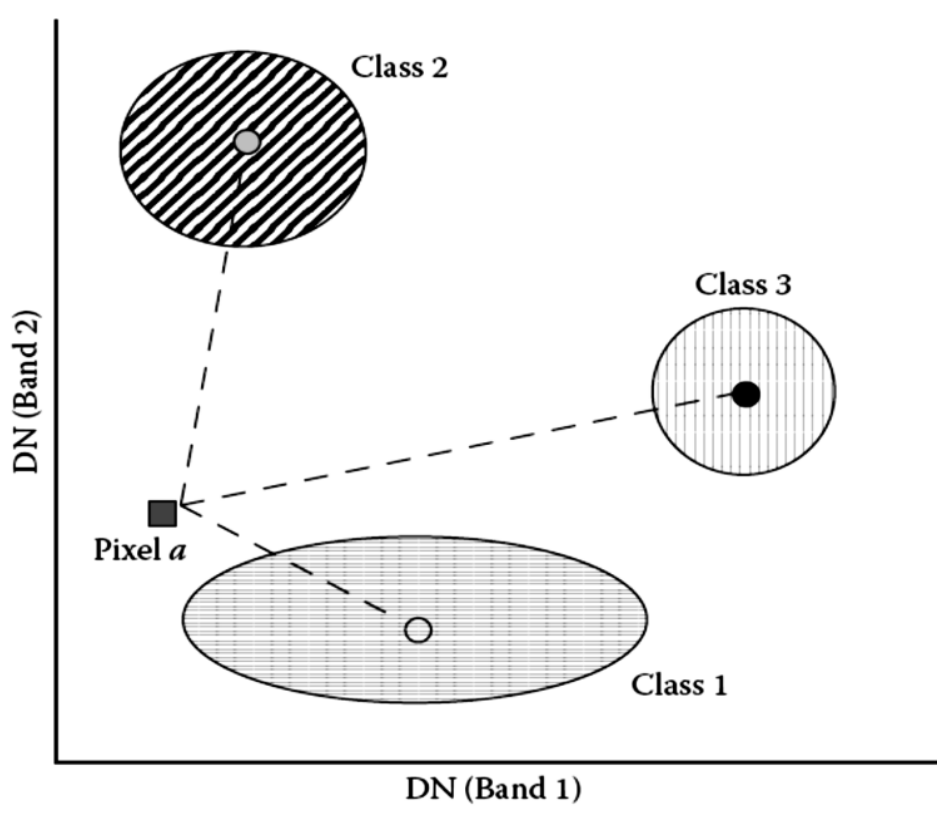

Figure 2. Classification algorithm of minimum distance to mean (Source, Gao, 2009).

The calculation of the Euclidean distance from one point to the average class in the band is as the following: (equation 1) (Navulur, 2007).

Equation 1.

$$
\text { Dist }=\operatorname{SQRT}\left[\left(\mathrm{BV}_{\mathrm{ij}} \mathrm{k}-\mu \mathrm{ck}\right)^{2}+\left(B V_{\mathrm{ij}} \mathrm{l}-\mu \mathrm{cl}\right)^{2}\right]^{1}
$$

where $\mu \mathrm{ck}$ and $\mu \mathrm{cl}$ are average vectors of class $\mathrm{c}$ measured in band $\mathrm{k}$ and 1 .

\section{3. Classification algorithm of maximum likelihood}

The classification of maximum likelihood is one of the most versatile methods, used in the supervised classes. This algorithm assesses variance and covariance of classes . For this, it is supposed that all the educational areas have normal transmittance. In fact, the educational classes samples should indicate that class. Hence, more samples should be used as much as possible so that the variations of the most of the spectral properties are included in this consistent realm. Normal distribution is bell shaped in which average, mean, and values index are equal. However, if reality is something else, the results won't be credible (Alavipanah, 2006). This method of classification is done during three stages:

1. Average vector calculations, variance and calculations for the classes in educational samples

2. Considering the disparity of average vector pixel through function of probabilities

3. Introducing all the data to classes that has the maximum likelihood of membership in that class

After assessing the probabilities in each class, pixels are assigned to classes, having the highest similarity (Alavipanah, 2006). 


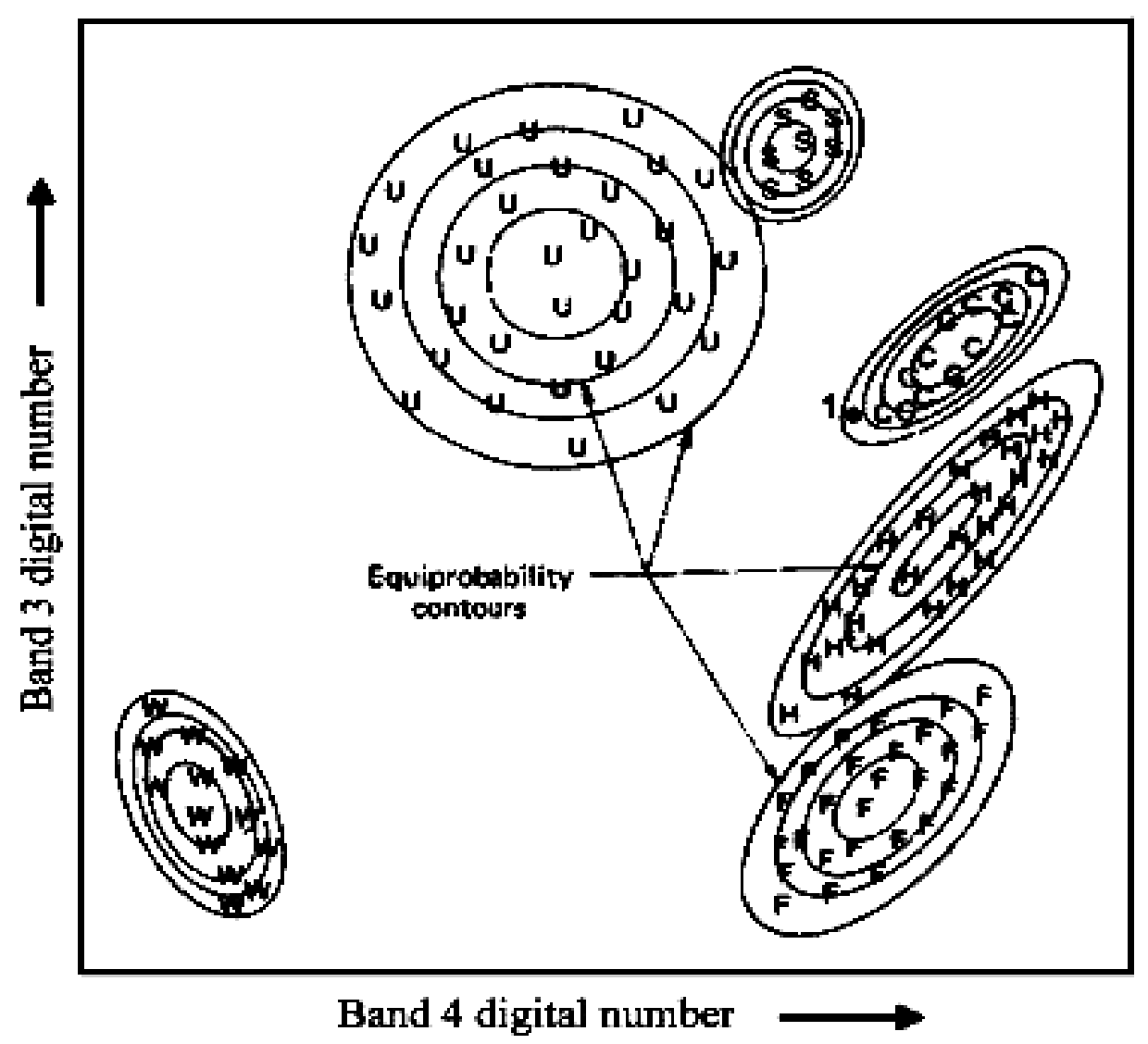

Figure 3. Classification using the algorithm of maximum probability (Lilesand, et al, 2004).

Generally speaking, in the maximum likelihood method oval levels will determine the assignment status of one pixel to a special class. For this, the variance and correlation calculations are used. (Alavipanah, 2006). In fact, statistical methods are the most common ways of classification as the subset of numerical and quantitative method. In the methods mentioned, a group of statistical properties as indices of similarity will divide the multi spectral space of satellite images to classes in use (Karami, 2002). The supposition of the primary equation is that these probabilities are the same for all the classes and incoming bands are normally distributed (Qian, et al, 2007). This classification method, is a standard method in the supervised classification that classifies unknown pixels in the classes in use to the density functions of the multivariate probability. The statistical properties of a set of educational data are used through the reference data for assigning the probabilities density functions in classes.

Mathematically speaking, this logic is shown as:

$$
x \in \omega_{i} \quad \text { if } \quad p\left(\omega_{i} / x\right)>p\left(\omega_{j} / x\right) \quad \text { for all } j \neq i
$$

Which means the pixel with spectral values vector of $x$ belongs to the class $\omega_{i}$, in case, the probability value belonging to the pixel of this class, i.e. $\mathrm{p}\left(\omega_{\mathrm{i}} / \mathrm{x}\right)$ is greater than the probability off other classes. This classification method is based on the Bayesian probability formula (Equation 2). 
Equation: 2.

$$
\mathrm{p}(\mathrm{X}, \mathrm{w})=\mathrm{p}(\mathrm{w} / \mathrm{X}) \mathrm{P}(\mathrm{X})=\mathrm{P}(\mathrm{X} / \mathrm{w}) \mathrm{p}(\mathrm{w})
$$

where $\mathrm{P}(\mathrm{X}, \mathrm{w})$ is the occurrence probability of $\mathrm{x}$ and $\mathrm{w} ; \mathrm{p}(\mathrm{x})$ and $\mathrm{p}(\mathrm{w})$ is the primary probability of the class $\mathrm{x}$ and $\mathrm{w} ; \mathrm{p}(\mathrm{w} / \mathrm{x})$ is the conditioned probability of the $\mathrm{x}$ occurrence in the $\mathrm{w}$ occurrence. After calculating different law elements, one can produce a probabilities vector that engenders making decisions. Thus, the algorithms of this classification is calculating these elements and comparing the secondary probability of different classes with another (Fatemi and Rezaee, 2006).

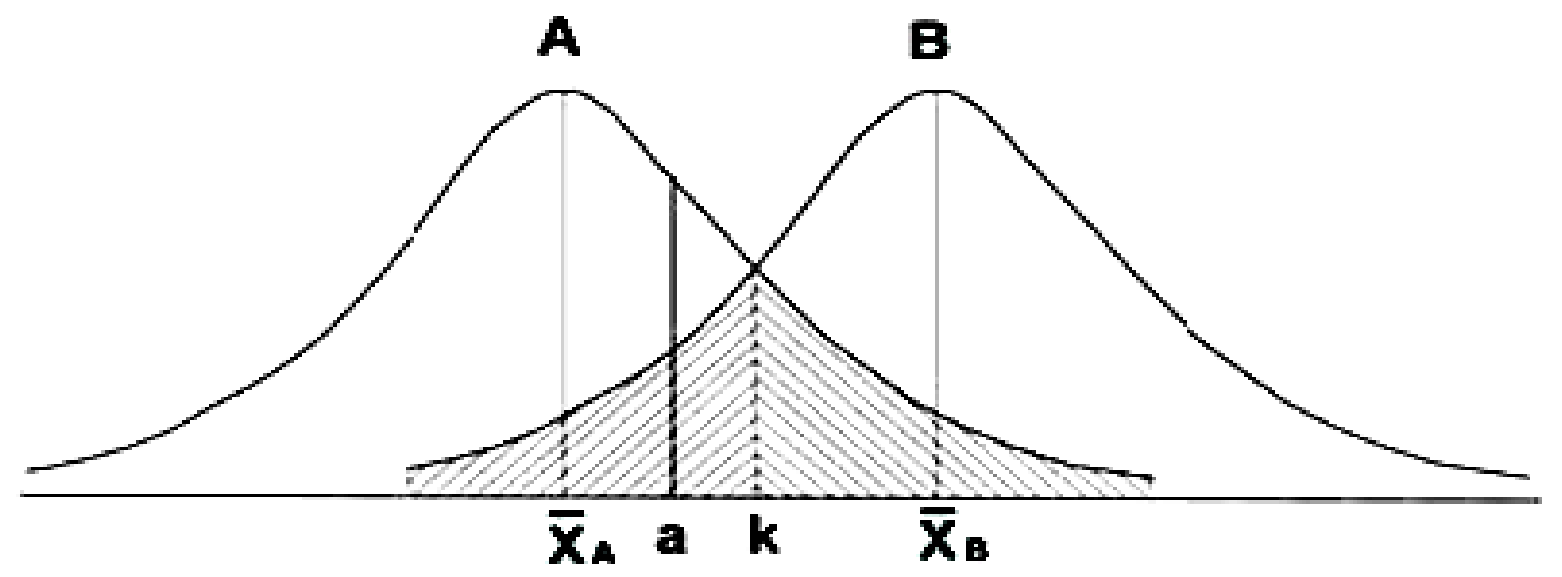

Figure 4. The rule of decision making of the classifier of maximum probability.

\section{4. Classification method of parallel piped}

The parallel piped algorithm is used when the image is multi band (Eastman, 2006). The parallel piped classifier often called multiple alignments distinguisher divides each of the space of the multi spectral paradigms to sections.

The region for decision making for each order is defined and determined based on the least and most values on any axis. The accuracy of this type of classification is based on the choice of the least and most values under question with regards o the demographic statistics of each class. For this, better understating of the population distribution of each class is of high importance.

Furthermore, compared to other classification methods, the time to calculate is very low in this classification. Here, in this classification, an unknown pixel based on the class category or that of decision, is classified. Observations of the unknown pixels occur in the overlay regions are ordered as insecure or placed optionally in one of two overlay classes or in both overlay classes (Lillesand and Kifier, trans. By Malmiran, 2001). Figure 5, shows the parallel piped classification algorithm. 


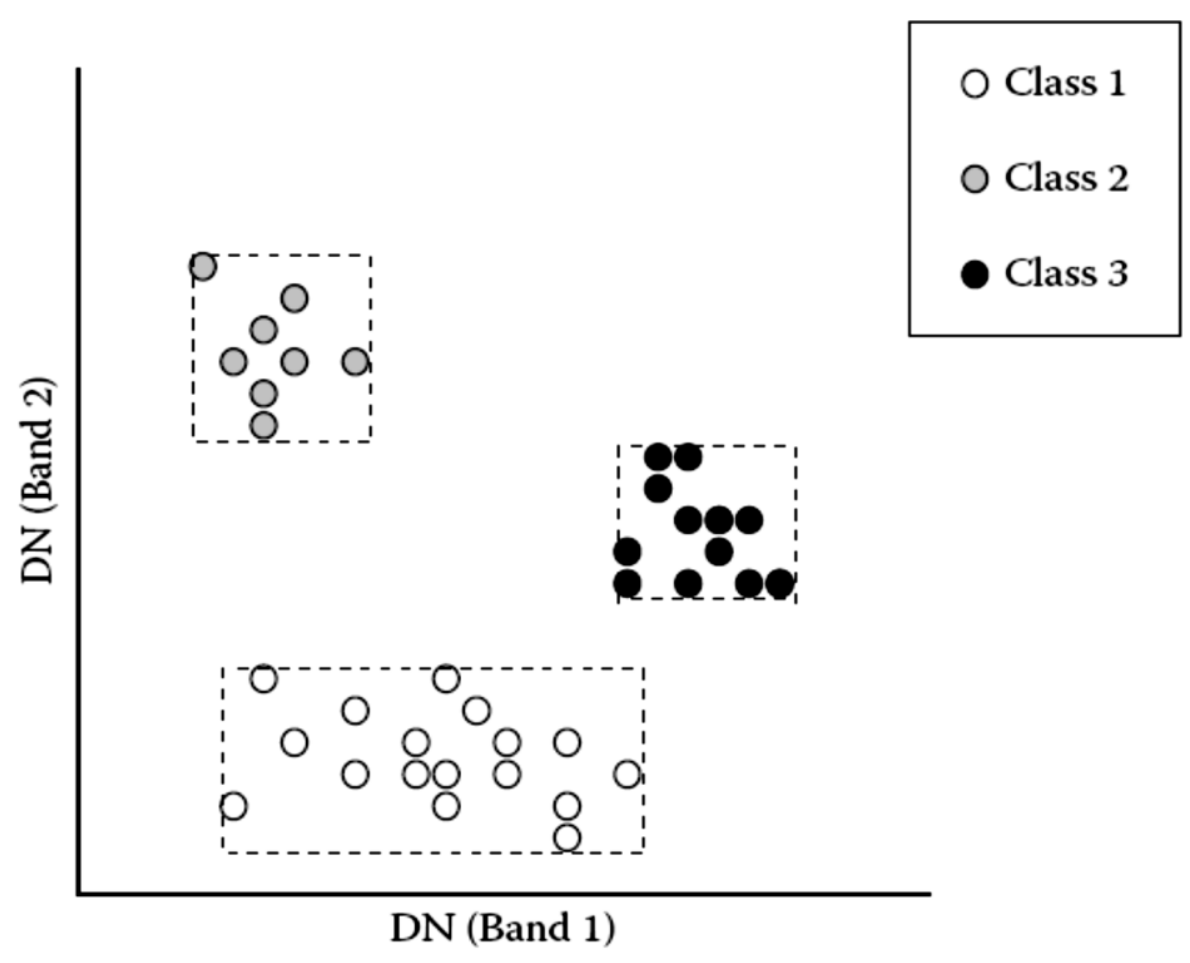

Figure 5. The classification algorithm of the parallel piped (Source, Gao, 2009).

From among the supervised classification methods, the parallel piped classifier demands little information from the user. The user provides an estimation of minimum and maximum pixel values in each band and for each of the predetermined classes. These two extremes provides the minimum and maximum possibility of locating the limits of each of the parallel piped. In this method, each of the unknown pixels is controlled and compared based on choice and numerical values so that its position is determined in one of the parallel piped.

\section{5. Assessing accuracy}

In assessing accuracy quantitatively, the purpose is to specify and measure map errors (Sugardian, 2000). Because, it is indicative of the way the classifier is used in extracting classes in question. Sometimes, in initial assessment, an easy optical examination could be used for probable assessment of the classified results. However, it is a subjective method and becomes hardly quantified.

The accuracy of classification is obtained by comparing the classified pixel sample with ground information (Lutfi Suzen, 2002). Choosing a series of clear sample pixels and comparing their labels, with classified results are the most common way for quantitative assessment of the accuracy of classifications. The accuracy of classification is gained by comparing the classified pixel samples with ground information. The results of this comparison are presented like error matrix, also, known as confusion matrix (Mahmood Zade, 2004). However, the error matrix is used for extracting additional information (Varshney, 2004).

In assessing the accuracy of thematic maps obtained from satellite images through the error matrix, the overall accuracy, Kappa coefficient, the accuracy of producer and user are measured (Navulur, 2007). The overall accuracy is an average of the classification accuracy, 
showing the ratio of proper classified pixels to the overall sum of clear pixels and is estimated like the equation 3 .

Equation 3:

$$
\mathrm{O} \cdot \mathrm{A}=\frac{\sum_{\mathrm{i}=1}^{\mathrm{c}} \mathrm{E}_{\mathrm{ii}}}{\mathrm{N}}
$$

where $\mathrm{c}$ is the number of classes, $\mathrm{N}$ is the overall number of clear pixels, $\mathrm{E}_{\mathrm{ii}}$ is the diametrical members of the error matrix and O.A. is the overall accuracy of the classification. Kappa is a disrupted multivariate technique that is statistically used for determining the fundamental differences of the error matrix in assessing the accuracy (Congalton, 2009). The Kappa coefficient shows that the significant difference of confusion matrix with results from classification is random.

The Kappa index values varies between 0 to 1 where, the closer it is to one, the closer the accuracy level of the map obtained from classification to reality (Abdi, 2005). If the value of $\mathrm{K}$ is one, that means completely correct classification while if then value of $\mathrm{K}$ is zero, then classification is fully random and if $\mathrm{K}$ is negative, that means weak classification. The Kappa index is calculated based on the equation 4 .

Equation 4:

$$
K=\frac{N \sum_{i=1}^{k} n_{i i}-\sum_{i=1}^{k} n_{i+} n_{+i}}{n^{2}-\sum_{i=1}^{k} n_{i+} n_{+i}}
$$

where, $\mathrm{n}_{\mathrm{ii}}$ is the matrix diametrical members , $\mathrm{n}_{+1}$ is the overall observations of the $\mathrm{i}$ array row and the $\mathrm{i}$ array column and $\mathrm{N}$ is the overall observations. The Kappa value provides the classification accuracy compared to a situation where an image is fully classified randomly. This means that after cancelling the effect of chance on classifying, the adaptability value is estimated with the ground reality.

The accuracy of user and that of the producer are two parameters defined to measure the classification accuracy for different classes separately. Both of them are estimated using the error matrix. The accuracy of the producer is indicative of the classification accuracy of pixels related to a special class in the ground reality map. The estimation of the producer's accuracy for each class is as the equation 5. The accuracy of the user is indicative of the classification probability of a special class in accordance with the same class in the ground reality map estimated as equation 6 .

Equation 5:

$$
\text { P. A. }=\frac{X_{j j}}{\sum_{i=1}^{r} X_{i j}}
$$

Equation 6:

$$
\mathrm{U} . \mathrm{A} .=\frac{\mathrm{X}_{\mathrm{ii}}}{\sum_{\mathrm{j}=1}^{\mathrm{r}} \mathrm{X}_{\mathrm{ij}}}
$$




\section{CONCLUSIONS}

The classification algorithms of minimum distance to mean , maximum probability and parallel piped were applied using the educational samples on the multi spectral image of the IKONOS satellite and were provided using the trial asestechnique (Richards, 2006). It's been an easy algorithm that requires little computational time. Should the pixel distance to the definite distance is greater in the analysis, it remains unknown or unclassified.

This classification does not measure different degrees among the class variances and thus, it has lower accuracy compared to the classification method of the maximum probability. In the parallel piped algorithm, in accordance with spectral range of the sample classes chosen on the image, the spectral values variance was estimated. Using the minimum and maximum spectral values of the sample classes in the bands of the images in question, tetragonals. The samples chosen are the same algorithm samples mentioned. While and hence, classified as unknown pixels. Also, there were pixels classified $n$ more than one class. The accuracy level obtained with this algorithm is lower compared to the two previous methods.

Table 2. Threshold changes of the land use classes in classifying the parallel piped.

\begin{tabular}{|c|c|c|c|c|}
\hline Value & Name & Color & Threshold & Bias \\
\hline 1 & $\begin{array}{c}\text { Orchards and } \\
\text { trees }\end{array}$ & & 1 & 1 \\
\hline 2 & $\begin{array}{l}\text { Residential } \\
\text { areas }\end{array}$ & & 1 & 1 \\
\hline 3 & Roads & & 1.5 & 1 \\
\hline 4 & Industrial areas & & 0.76 & 1 \\
\hline 5 & $\begin{array}{l}\text { Arid farming } \\
\text { lands }\end{array}$ & & 1 & 1 \\
\hline 6 & Arid urban lands & & 1 & 1 \\
\hline 7 & $\begin{array}{l}\text { Green zones and } \\
\text { cultivated areas }\end{array}$ & & 0.5 & 1 \\
\hline
\end{tabular}

Table 3. Chart 2. show the statistical parameters of the accuracy assessment obtained of the error matrix algorithms and maps 1,2, and 3 present the results of the final classification of the image for the algorithm.

\begin{tabular}{|c|c|c|c|c|c|c|c|c|c|}
\hline \multirow{2}{*}{ Class } & \multicolumn{3}{|c|}{ Parallel piped } & \multicolumn{3}{c|}{ Minimum distance to mean } & \multicolumn{3}{c|}{ Maximum probability } \\
\cline { 2 - 10 } & $\begin{array}{c}\text { Producer's } \\
\text { accuracy } \\
(\%)\end{array}$ & $\begin{array}{c}\text { User's } \\
\text { accuracy } \\
(\%)\end{array}$ & Kappa & $\begin{array}{c}\text { Producer's } \\
\text { accuracy } \\
(\%)\end{array}$ & $\begin{array}{c}\text { User's } \\
\text { accuracy } \\
(\%)\end{array}$ & Kappa & $\begin{array}{c}\text { Producer's } \\
\text { accuracy } \\
(\%)\end{array}$ & $\begin{array}{c}\text { User's } \\
\text { accuracy } \\
(\%)\end{array}$ & Kappa \\
\hline $\begin{array}{c}\text { Orchard and } \\
\text { trees }\end{array}$ & $83 / 842$ & $89 / 505$ & $0 / 8784$ & $93 / 898$ & $78 / 32$ & $0 / 749$ & $92 / 09$ & $84 / 85$ & $0 / 825$ \\
\hline
\end{tabular}




\begin{tabular}{|c|c|c|c|c|c|c|c|c|c|}
\hline $\begin{array}{l}\text { Residential } \\
\text { areas }\end{array}$ & $64 / 793$ & $94 / 922$ & 0/9291 & $81 / 277$ & $78 / 83$ & $0 / 705$ & $90 / 94$ & $92 / 38$ & 0/894 \\
\hline Roads & $69 / 892$ & $79 / 97$ & $0 / 7716$ & $88 / 868$ & $59 / 61$ & $0 / 54$ & $83 / 56$ & $89 / 8$ & $0 / 884$ \\
\hline $\begin{array}{l}\text { Industrial and } \\
\text { workshops }\end{array}$ & $15 / 347$ & $99 / 367$ & 0/9931 & $56 / 305$ & $94 / 43$ & $0 / 94$ & $92 / 67$ & $70 / 64$ & $0 / 681$ \\
\hline $\begin{array}{l}\text { Arid farming } \\
\text { lands }\end{array}$ & $95 / 948$ & 64 & $0 / 602$ & $68 / 395$ & $72 / 76$ & $0 / 699$ & $97 / 41$ & $85 / 31$ & $0 / 838$ \\
\hline $\begin{array}{l}\text { Arid urban } \\
\text { lands }\end{array}$ & $93 / 063$ & $93 / 013$ & $0 / 9183$ & $82 / 818$ & $95 / 86$ & $0 / 952$ & $86 / 93$ & $99 / 66$ & 0/996 \\
\hline $\begin{array}{c}\text { Green and } \\
\text { cultivation } \\
\text { lands }\end{array}$ & $59 / 391$ & $96 / 252$ & $0 / 9566$ & $67 / 851$ & $94 / 5$ & $0 / 936$ & $80 / 88$ & $93 / 48$ & $0 / 924$ \\
\hline $\begin{array}{l}\text { Overall } \\
\text { accuracy }\end{array}$ & \multicolumn{3}{|c|}{$70 / 403$} & \multicolumn{3}{|c|}{$79 / 059$} & \multicolumn{3}{|c|}{$88 / 93$} \\
\hline Overall Kappa & \multicolumn{3}{|c|}{$0 / 659$} & \multicolumn{3}{|c|}{$0 / 747$} & \multicolumn{3}{|c|}{$0 / 867$} \\
\hline
\end{tabular}

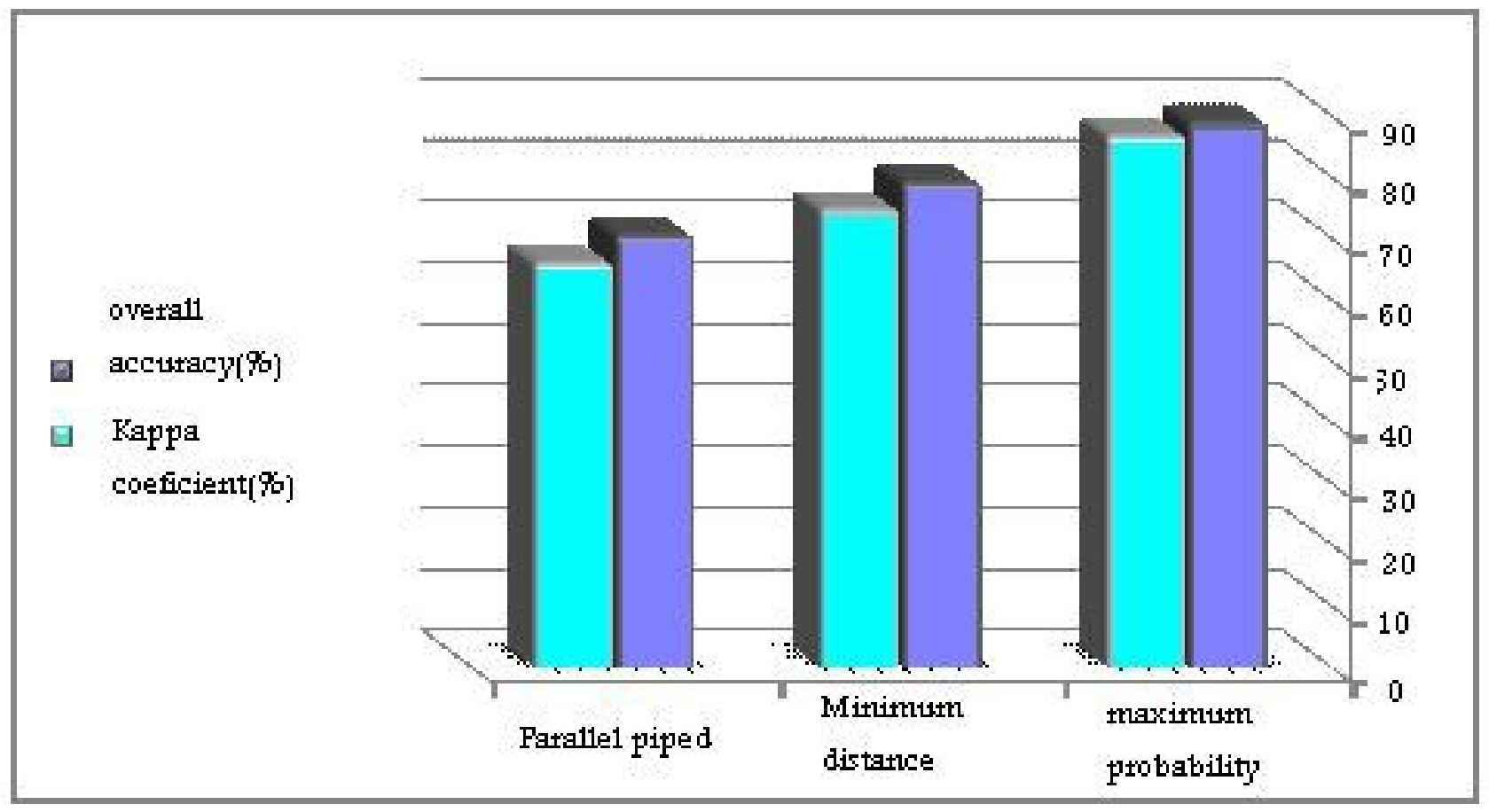

Chart 2. Comparing the Kappa coefficient and the overall accuracy of the pixel-based classification algorithms. 


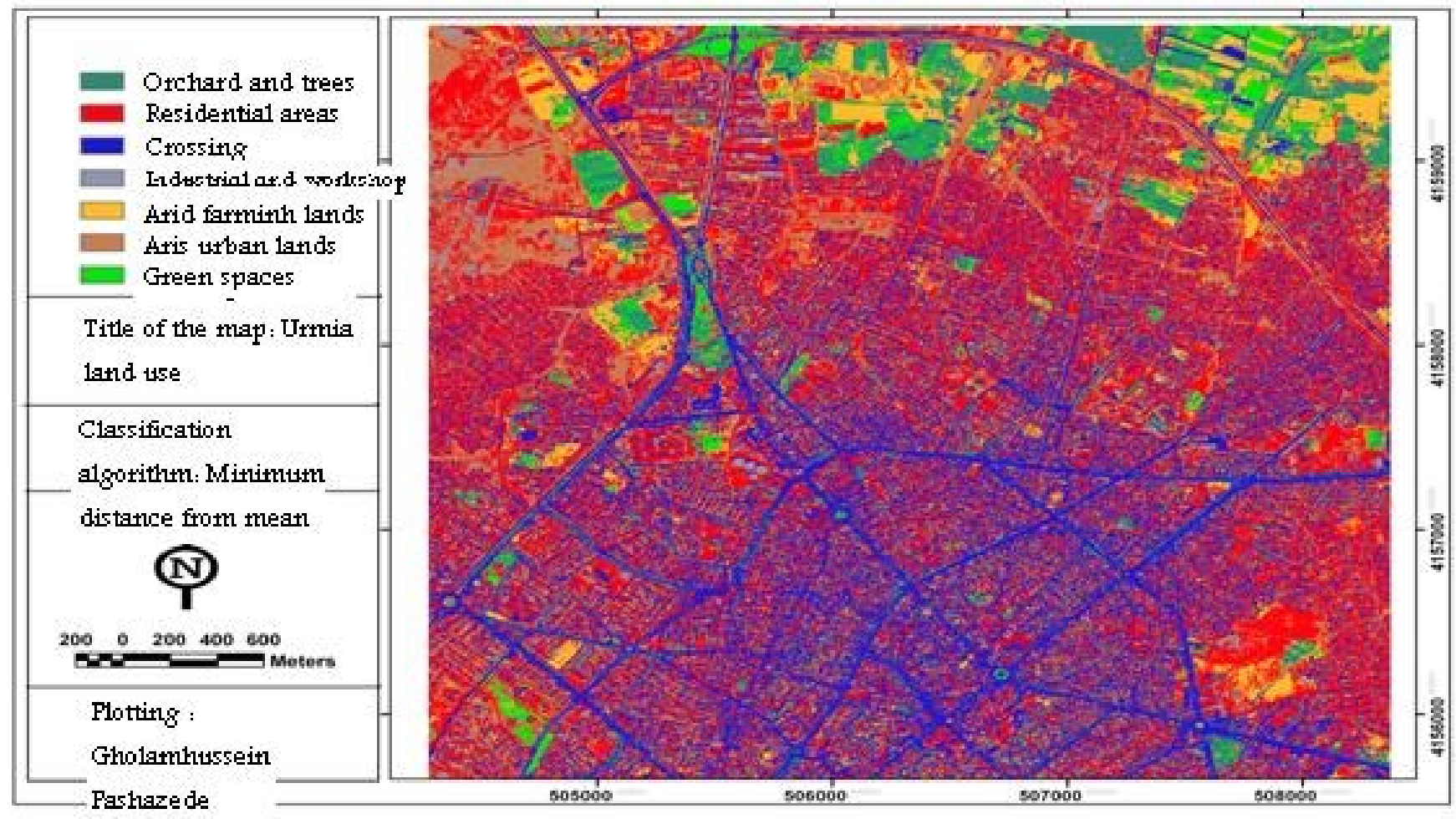

Map 1. Classified land use with the algorithm of minimum distance to mean.

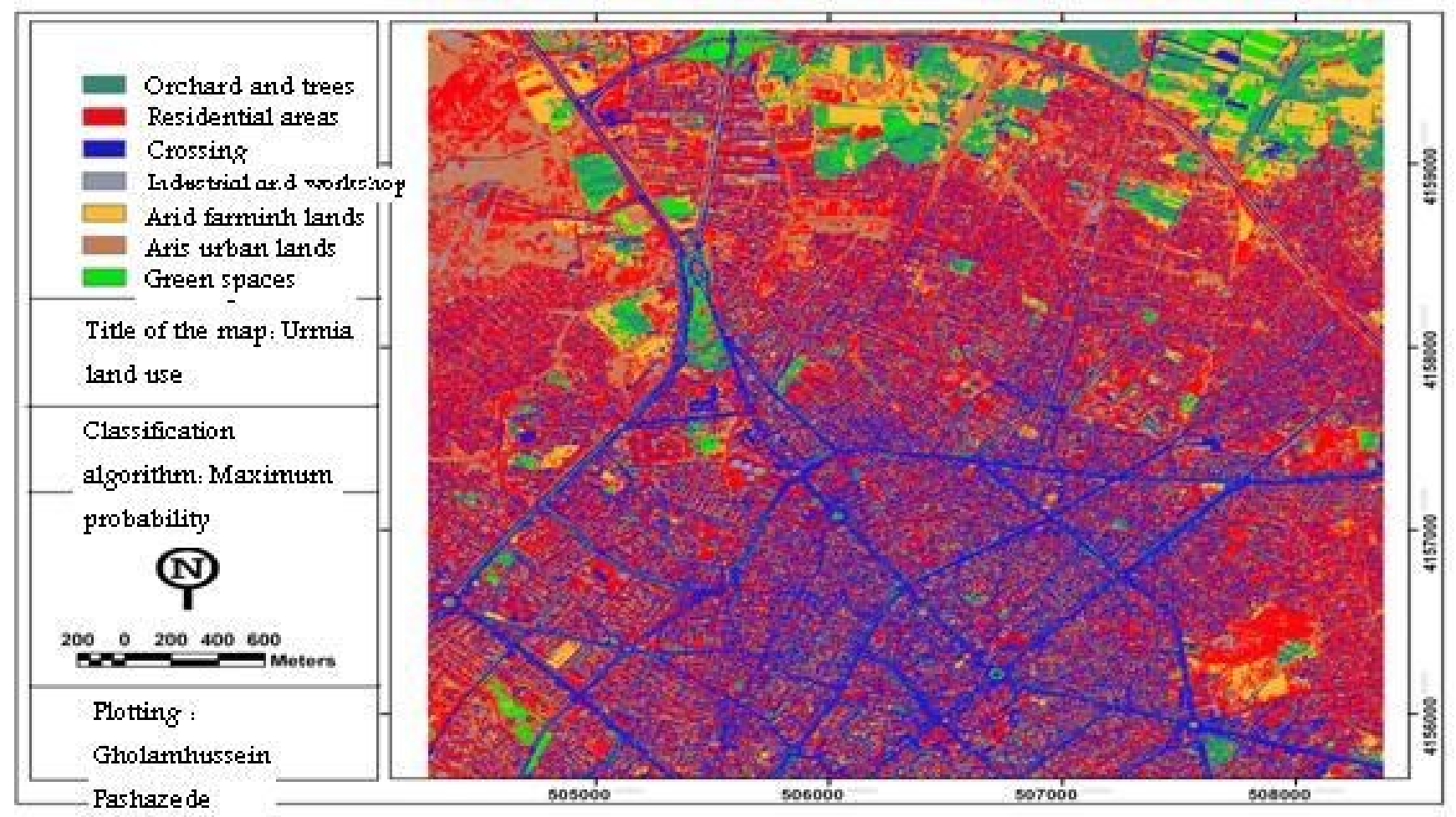

Map 2. Classified land use with the algorithm of the maximum probability. 


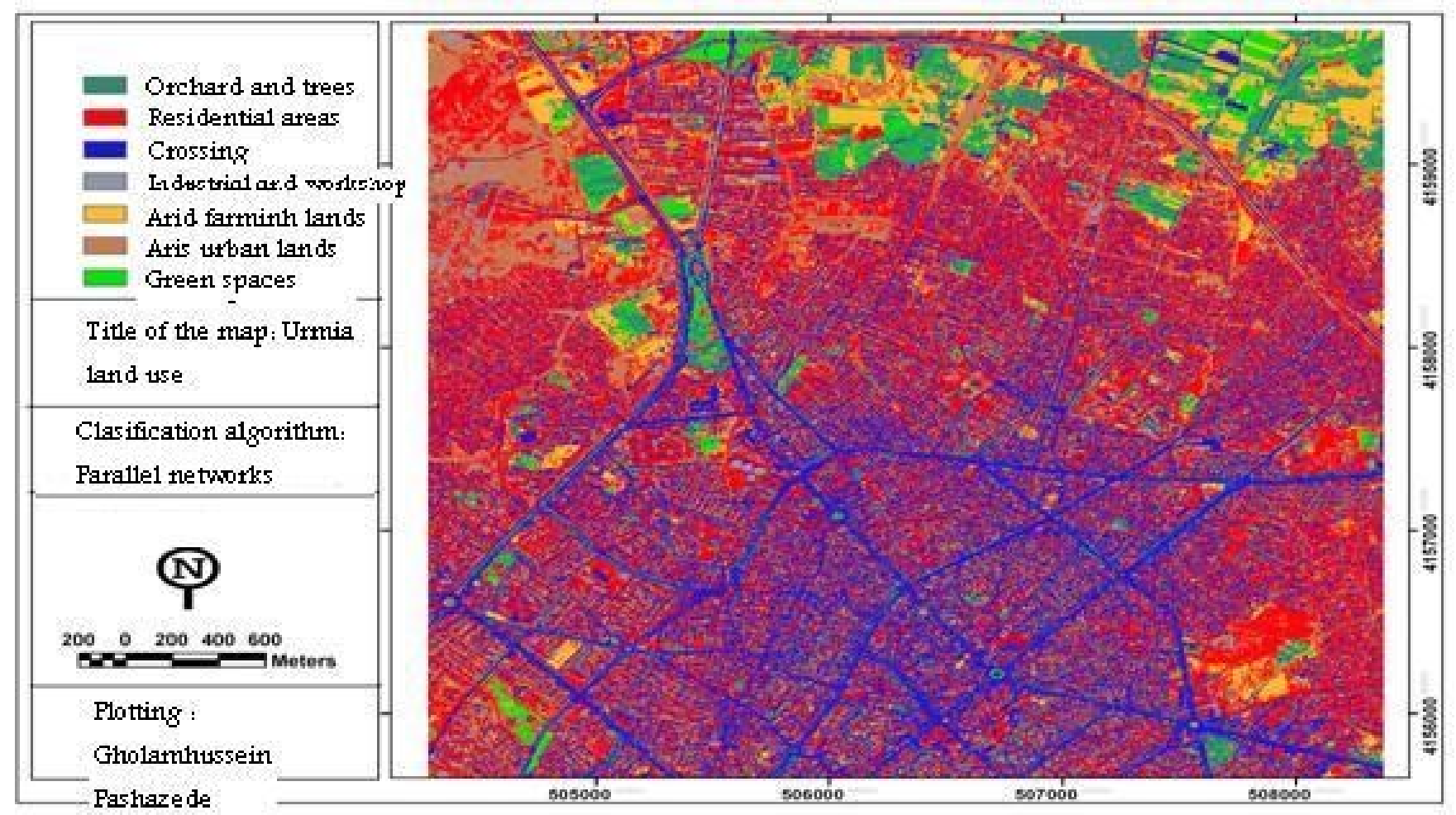

Map 3. Classified land use with the parallel piped algorithm.

Given the results obtained of the accuracy of the classification methods, it is observed that the classification algorithm of the maximum probability , minimum distance and parallel piped have an overall accuracy of 88/93 \%, 79/059\% and 70/403 \% respectively.

Also, the Kappa coefficient obtained for the mentioned classification methods is like their overall accuracy, i.e. the maximum Kappa coefficient for the classification algorithm of maximum probability is $0 / 747$, minimum distance is $0 / 659$ while the parallel piped classification method is $0 / 659$.

The results obtained of the pixel-based algorithms indicate that the classification algorithm of maximum probability has better accuracy with respect to the overall accuracy and the Kappa coefficient while from among this, the parallel piped classification method has lower accuracy. Also, among the three mentioned algorithms, the least and most user's accuracy for the road class is $59 / 61 \%$ in the classification algorithm of minimum distance from the mean and for the urban arid land class, it is $99 / 63 \%$ in the classification algorithm of maximum probability, while the producer's accuracy is $15 / 34 \%$ for the industrial areas in the classification algorithm of maximum probability.

The items above indicate that in the classification algorithm of maximum probability, $97 / 4 \%$ of the arid farming land are identified properly and the user' accuracy of it is $3 / 85 \%$. In other words, $3 / 85 \%$ of the farming lands are in this category. The maximum interference of pixels existing in the classification algorithm, the maximum probability is between green spaces and cultivated lands class and orchard and trees class. Concerning the classification algorithm of the minimum distance from mean, the maximum interference is between the road class and residential class while in the parallel piped algorithm, the same values is between the residential areas and arid farming lands. 


\section{Recommendation}

- Based on the results of this research, the importance of the application of remote sensing technology for prevention of national resource waste becomes evident and finally it is recommended that this technology be taken into account by planners and managers.

- These maps have numerous capabilities for managing and helping the planning objectives. Through conducting temporal series of land use maps and cover with high resolution, we can better understand the changes trend.

\section{References}

[1] Japanese remote sensing association (1993). Remote sensing basics, trans, by Jahedi,Farshid and Farokhi, Shahrokh, (First version, Iranian remote sensing Publications).

[2] Pashazadee, Gholamhussein (2009). Comparing the pixel-based and object-oriented methods in classifying the urban land use, using the remote sensing data (Case study, Urmia), M.A thesis, Geology sciences faculty, Shahid beheshti university, Tehran

[3] Zobeiri Mahmood, Majd Alireza (2003). Familiarity with the remote sensing technique and its application in the natural sources(satellite information, spac nd arial images), Fourth version, Tehran university publications.

[4] Abdi Parviz (2005). Identification and evaluation of forest lands, using RS-GIS in Zanjan, Geomatic conference in geology, Second version, Tehran university publications), The application of remote sensing in geology, Second version, Tehran university publications.

[5] Alavipanah Seid Kazem (2006). The application of remote sensing in geology, second version, Tehran university publications.

[6] Alavipanah, Seid Kazem, Matinfar Hamidreza, Rafieemam Ammar (2008). The application of IT in geology, Radar, supra and multiple spectral remote sensing statistics earth, First version, Geographic information systems, Nervous networks, phase sets an statistics earth, Tehran university publications.

[7] Fatemi Seidbagher; Rezae Yousef (2008). Remote sensing basics, Azade publications.

[8] Karami, Jalal (2003), Objects - oriented classification of Land sat ETM+ OF Malayer region based on size in the artificial nervous networks, M.A. thesis, Humanities Faculty, Tarbyt Modaraes University.

[9] Mahmoodzade Hasan (2004). The application of multi temporal satellite data in the GIS with the aim of investigating land use changes of Tabriz, M.A. thesis, Humanities Faculty, Tabriz University.

[10] Congalton R. G., Green K. (2009). Assessing the Accuracy of Remotely Sensed Data: Principles and Practices, Second Edition, CRC Press, Taylor \& Francis Group.

[11] Gao J. (2009). Digital Analysis of Remote Sensing Imagery, McGraw-Hill Companies, Inc. 
[12] Herold M., Scepan J. (2002). Object-oriented mapping and analysis of urban land use/cover using IKONOS data, Proceedings of 22nd EARSEL Symposium "Geoinformation for European-wide integration", Prague.

[13] Janssen L. L. F. (2001). Principles of Remote Sensing An introductory textbook, Second Edition, ITC Educational Textbook Series, Enschede, The Netherlands.

[14] Lillesand T. M., Kiefer R. W., Chipman J. W. (2004). Remote Sensing and Image Interpretation, fifth Edition, John Wiley \& Sons, Inc.

[15] Lutfi Suzen M. (2002). Data Driven Landslide Hazard Assessment Using Geographical Information Systems and Remote Sensing, Doctor Thesis, Department Of Geological Engineering, School Of Natural And Applied Sciences, Middle East Technical University, Turkey.

[16] Matinfar R., Sarmadian F., Alavi Panah S. K., Heck R. American-Eurasian J. Agric. \& Environ. Sci. 2(4) (2007) 448-456.

[17] Navulur K. (2007). Multispectral Image Analysis Using the Object-Oriented Paradigm, CRC Press Taylor \& Francis Group.

[18] Qian, J., Zhoua Q., Houa Q. (2007). Comparison Of Pixel-Based And Object-Oriented Classification Methods For Extracting Built-Up Areas In Arid zone, ISPRS Workshop on Updating Geo-spatial Databases with Imagery \& The 5th ISPRS Workshop on DMGISs

[19] Richards J. A., Jia X. (2006). Remote Sensing Digital Image Analysis An Introduction, 4th Edition, Springer-Verlag Berlin Heidelberg.

[20] Taubenböck H., Esch T., Roth A. (2006). An Urban Classification Approach Based On An Object-Oriented Analysis Of High Resolution Satellite Imagery For A Spatial Structuring Within Urban Areas, 1st EARSeL Workshop of the SIG Urban Remote Sensing, Humboldt-Universität zu Berlin.

[21] Varshney P. K., Arora M. K. (2004). Advanced Image Processing Techniques for Remotely Sensed Hyperspectral Data, Springer Verlag, Berlin. 